\title{
Crenças Maternas sobre o Desenvolvimento Sociocomunicativo de Bebês
}

\author{
Cristiane Gabriel de Souza \\ Secretaria Municipal de Saúde de São José do Egito, São José do Egito, Pernambuco, Brasil \\ Gabriela Marcolino Alves Machado \\ Laísy de Lima Nunes \\ Fabíola de Sousa Braz Aquino' \\ Programa de Pós-graduação em Psicologia Social da Universidade Federal da Paraíba,
} João Pessoa, Paraíba, Brasil

\begin{abstract}
Resumo
As crenças maternas são representações internas que guiam o comportamento da mãe em relação ao bebê. Este estudo investigou as crenças acerca do desenvolvimento sociocomunicativo de bebês nos três primeiros meses de vida. Participaram do estudo 20 mães, residentes na cidade de Campina Grande-PB, de diferentes níveis socioeconômicos. Foi realizada uma entrevista semiestruturada, gravada e transcrita de forma literal. Os resultados indicam variações nas crenças maternas em função do seu nível instrucional e da idade dos bebês e demonstram que a maioria das mães concebe que o modo de cuidar do seu filho influencia o desenvolvimento infantil. As mães acreditam que desde os primeiros meses após o nascimento, o bebê é capaz de compreender acontecimentos do meio no qual vive e de se comunicar com as mesmas. Esses resultados oferecerem novas informações para a literatura e podem subsidiar o planejamento de políticas públicas através de programas de orientação sobre desenvolvimento infantil às mães.
\end{abstract}

Palavras-chave: Desenvolvimento sociocomunicativo, interação mãe-bebê, crenças maternas.

\section{Maternal Beliefs about the Sociocommunicative Development of Babies}

\begin{abstract}
The maternal beliefs are internal representations that guide the mother's behavior of regarding the babies. This study investigated the maternal beliefs about the development sociocommunicative of babies in the first three months of life. The study included 20 mothers living in city of Campina Grande-PB, from different socioeconomic levels. We performed a semi-structured interview, recorded and transcribed literally. The results indicate variations in maternal beliefs according to the instructional level and maternal age of babies and show that most mothers who conceive how to care for their child influences child development. Mothers believe that since the first months after birth the baby is able to understand events of the environment in which he lives, and to communicate with it. These results contribute to data

Endereço para correspondência: Rua Mário Batista Junior, 75, Ed. Quinta Avenida, Apto. 301, Bairro Miramar, João Pessoa, PB, Brasil 58043130. E-mail: cris_sje@hotmail.com, gabriela_marcolino@hotmail. com, la.laisy@hotmail.com e fabiolabrazaquino@gmail.com

Este artigo é derivado do Trabalho de Conclusão de Curso (TCC) desenvolvido pela primeira autora em 2009.
\end{abstract}


collection that can provide new information to the literature and support the planning of public policies through guidance programs on child development for mothers.

Keywords: Sociocommunicative development, mother-baby interaction, maternal beliefs.

\section{Creencias Maternas sobre el Desarrollo Sociocomunicativo de los Bebés}

\section{Resumen}

Las creencias maternas son representaciones internas que guían el comportamiento de la madre sobre el bebé. Este estudio investigó las creencias sobre el desarrollo sociocomunicativo de los bebés en los tres primeros meses de vida. El estudio incluyó a 20 madres que viven en la ciudad de Campina Grande - PB, de diferentes niveles socioeconómicos. Se realizó una entrevista semi-estructurada, grabadas y transcritas literalmente. Los resultados indican que las variaciones en las creencias maternas según su nivel de instrucción y la edad de los bebés y muestran que la mayoría de las madres conciben que la forma de cuidar de su hijo influyen en el desarrollo infantil. Las madres creen que desde los primeros meses después del nacimiento, el bebé es capaz de comprender los acontecimientos de su entorno y para comunicarse con él. Estos resultados proporcionan nueva información a la literatura y pueden soportar la planificación de las políticas públicas a través de los programas de orientación a las madres sobre el desarrollo infantil.

Palabras clave: Desarrollo sociocomunicativo, la interacción madre-hijo, creencias maternas.

O estudo das crenças parentais tem se tornado um tópico importante na psicologia do desenvolvimento e despertado muitos questionamentos na compreensão do desenvolvimento infantil à medida que estabelece uma relação com as práticas parentais e a qualidade do cuidado e das interações com a criança. Em geral, o conhecimento acerca do desenvolvimento infantil tem influência significativa na interação entre pais e filhos; esse conhecimento engloba, entre outros aspectos, crenças acerca dos períodos mais prováveis para aquisição de habilidades motoras, sociocomunicativas, perceptuais e cognitivas (Magalhães, 2007; Ribas, Seidl de Moura, \& Bornstein, 2007; Seidl de Moura, Ribas, Seabra, et al., 2004; Zamberlan, 2002).

Sobre esse tema, Harkness e Super (1996, 2006) afirmam que estudar as crenças parentais possibilita o entendimento acerca de seu impacto no desenvolvimento infantil. Nesse sentido, esses autores utilizam o conceito de nichos de desenvolvimento. Conforme seus estudos, o desenvolvimento da criança ocorre em um nicho ou contexto cujo eixo central é o lar da criança, onde ela vive com a família, sendo esta família o elemento mediador entre a criança e o meio físico e social. Esse nicho se relaciona com os costumes estabelecidos histórica e culturalmente sobre os modos de cuidar da criança, e com a psicologia dos cuidadores, que inclui as crenças pessoais de quem cuida da mesma.

Harkness e Super (1996) adotam a terminologia "Etnoteorias Parentais" para se referirem às crenças que correspondem aos modelos culturais que os pais possuem para julgar crianças, famílias e a si próprios como pais. As crenças parentais são frequentemente implícitas, tomadas como ideias tácitas sobre a forma "natural" ou "correta" de pensar ou agir.

Para Piovanotti (2007) essas crenças influenciam as percepções dos pais sobre os bebês e seu desenvolvimento. Dessa forma, as crenças atuam ainda como mediadoras da dinâmica familiar, influenciando as práticas de cuidado parental, o que repercute no comportamento e no desenvolvimento infantil (Ribas et al., 2007; Seidl de Moura, Ribas, Seabra, et al., 2004; Zamberlan, 2002). 
Outros autores, como Kobarg, Vieira e Sachetti (2006) ponderam que as crenças são formadas a partir das interpretações da realidade na qual o sujeito vive, e são desenvolvidas em um contexto específico, em um determinado local e tempo, sendo cultural e historicamente construídas a partir das interações sociais dos pais com outros membros do seu grupo social ao longo do tempo. No contexto cultural, as crenças não necessariamente determinam as ações dos indivíduos, mas podem orientar o comportamento deles e facilitar as suas reflexões a respeito das suas próprias crenças (Magalhães, 2007). Segundo Kobarg e Vieira (2008) as crenças indicam que o contexto ecológico, social e cultural em que vivem acaba, de alguma forma, interferindo no que as mães pensam.

Assim, é oportuno mencionar fatores que podem estar relacionados às crenças e aos comportamentos maternos, entre eles destaca-se o nível educacional das mães. Estudos mostraram que mães com um maior nível instrucional, apresentaram um maior conhecimento sobre o desenvolvimento infantil (Kobarg \& Vieira, 2008; Ribas et al., 2007; Seidl de Moura, Ribas, Piccinini, et al., 2004). Esse conhecimento está relacionado com as crenças das mães acerca da aquisição das habilidades motoras, perceptuais e cognitivas ao longo do desenvolvimento. Essa percepção por parte das mães torna-se importante por influenciar a forma como a mãe interage com seu bebê. Dito de outra forma, se a mãe acredita que um bebê de três meses não é capaz de se comunicar, ela provavelmente não irá conversar com ele, o que irá influenciar e, possivelmente, postergar o desenvolvimento do mesmo.

Nas discussões sobre essa temática, perspectivas socioculturais destacam o papel do vínculo afetivo do bebê com o outro para a constituição da criança. $\mathrm{O}$ vínculo seria, por um lado, promovido pela afetividade e emoção que contagiam e colocam as pessoas em uma interação recíproca. As interações sociais incentivam o surgimento de emoções, conflitos e negociações no grupo social, levando a movimentos mútuos de co-construção e mudanças pessoais e situacionais. Desta forma, o comportamento dos bebês se constrói socioculturalmente conforme as significações e interações do grupo social (Amorim, Costa, Rodrigues, Moura, \& Ferreira, 2012; Rossetti-Ferreira \& Costa, 2012).

Ainda a respeito do vínculo afetivo mãe-bebê, em outra perspectiva teórica, Bowlby (1984/2002) menciona a importância de a criança crescer numa relação de apego com a mãe para que haja um bom desenvolvimento do apego refletindo em um bom desenvolvimento afetivo, social e cognitivo da criança. Este autor afirma que os cuidados maternos estão intimamente ligados ao comportamento de apego, pois o ato de cuidar do bebê faz com que a mãe esteja constantemente próxima do mesmo, quase sempre ao alcance da sua vista ou dos seus ouvidos, de forma que ela está atenta às necessidades do seu filho e pode supri-las quando for preciso.

No que se refere, especificamente, às habilidades sociocomunicativas, a comunicação da díade mãe-bebê começa muito antes das primeiras palavras, quando eles se engajam em trocas face-a-face (Striano \& Reid, 2006). É possível observar indícios de uma comunicação entre a díade desde o início da vida do bebê, por meio de sorrisos e olhares. Desta forma, a comunicação infantil é sugerida a partir de seus gestos, e a dimensão socioafetiva é a primeira forma de linguagem usada pelos bebês (Mendes \& Seidl de Moura, 2009; Nogueira \& Seidl de Moura, 2007; Trevarthen \& Aitken, 2001).

Para Striano e Reid (2006) há uma predisposição dos bebês à comunicação e à interação social, nas situações diádicas ou triádicas. Em relação a esse aspecto, Legerstee (2013) esclarece que as competências precoces dos bebês estão relacionadas à atenção e à discriminação do ambiente, e que os mesmos respondem seletivamente a estímulos sociais. Desde as primeiras semanas de vida, o infante está aprendendo a sorrir e emitir sons, e possui formas eficientes de se comunicar com os parceiros sociais (Trevarthen, 1979). Pesquisadores como Gratier e Trevarthen (2007) afirmam que com seis semanas os bebês usam vocalizações e movimentos corporais para se comunicarem. Entre um e dois meses são capazes de olhar, ouvir e tocar objetos, o que demonstra uma habilidade rudimentar de atividade inteligente, caracterizando a 
subjetividade de bebês para lidar com o mundo. Nas interações face a face criam intercâmbio em sincronia e alternância, compartilhando muitas emoções. De acordo com Cleveland, Schug e Striano (2007), ao final do segundo mês, os bebês mostram sinais claros de diferenciação entre si e o mundo e são capazes de explorar e contemplar as consequências de suas ações no meio. O temperamento também começa a ser revelado nessa fase, o que torna possível diferenciar entre os bebês mais calmos e os mais agitados (Brazelton, 1994; Mendes \& Seidl de Moura, 2009).

Autores como Alvarenga e Piccinini (2007) e Pires (1990) lembram que o temperamento consiste em diferenças individuais nas tendências de comportamento que se apresentam precocemente e são relativamente estáveis através das situações e ao longo do tempo. Ele é também compreendido como um padrão inato, que se refere a diferenças constitucionais no nível de atividade física, no ritmo, na reação da criança a novas situações, na adaptabilidade, na intensidade da reação emocional e no humor na criança. Todavia, apesar de ser inato, o temperamento pode ser modificado por meio das interações sociais e culturais ao longo do desenvolvimento. Barbosa (2010) reitera que as dimensões do temperamento infantil e as práticas educativas maternas são marcadas por sua complexidade e são mutuamente influenciadas, ou seja, tanto o temperamento pode influenciar o comportamento do cuidador, quanto o comportamento do cuidador pode alterar tendências de temperamento da criança.

Bornstein (2013) e Bornstein e Tamis-LeMonda (1997) afirmam que desde o início da vida da criança, existe um sistema de comunicação recíproco, em que a mãe e o bebê tentam se comunicar e responder às necessidades um do outro. Sobre este sistema recíproco de comunicação da díade, dão o nome de responsividade, a qual se caracteriza pela presença de comportamentos maternos apropriados e relacionados aos comportamentos dos bebês. Tais autores destacam que a responsividade pode influenciar os aspectos socioemocionais e cognitivos da criança e ter repercussões diretas ou indiretas no crescimento infantil.
As novas habilidades e comportamentos dos bebês, possibilitados pelo aprimoramento e interligação do desenvolvimento sensorial, motor e cognitivo, são vistos e interpretados pela mãe, que passa a atribuir significado aos comportamentos dos bebês, interpretando-os como sinais comunicativos, mesmo que esse sentido ainda seja ignorado pela criança. As interações sociais em conjunto com as atribuições de significado possibilitam que o bebê tenha contato com o mundo cultural, e gradualmente seja inserido no universo simbólico e cultural (Pino, 2005).

Nas interações iniciais a atribuição de significado tem um importante papel para o desenvolvimento infantil, já que a partir dela o bebê internaliza, gradualmente, os significados de vários comportamentos comunicativos e vai se tornando capaz de fornecer respostas adequadas ao comportamento do adulto. A partir do momento que o bebê reconhece que pode exercer um efeito sobre o seu ambiente ele torna-se cada vez mais motivado a aprender, a controlar e interagir com o ambiente. Comportamentos como o choro, o sorriso e os gestos fornecem pistas para que os cuidadores, de modo especial, as mães, interpretem essas ações de acordo com o contexto, com as suas concepções sobre o desenvolvimento infantil, e as características específicas dos seus filhos (Pessôa, Seidl de Moura, \& Oliva, 2008; Seidl de Moura, 1999; Slaughter, Peterson, \& Carpenter, 2009).

Características individuais infantis, como a idade do bebê, também são importantes, na medida em que parecem influenciar as crenças e expectativas maternas. Resultados de estudos realizados por Seidl de Moura, Ribas, Piccinini, et al. (2004), demonstraram que quanto mais velho o bebê, maiores os conhecimentos da mãe sobre seus comportamentos, revelando que ao longo do desenvolvimento o bebê dá pistas para a mãe de seu futuro comportamento.

Diante do exposto, evidencia-se a relevância social e científica do estudo das crenças maternas sobre o desenvolvimento infantil, considerando que o levantamento acerca dessas crenças possibilita a compreensão sobre a qualidade dos cuidados e possíveis influências no desenvolvimento infantil, bem como permite abrir novos 
caminho para analisar a cultura e o desenvolvimento humano (Bandeira, Seidl de Moura, \& Vieira, 2009). Além disso, estudos que abordam essa temática podem trazer novas informações para a literatura e subsidiar práticas psicológicas em contextos de desenvolvimento e aprendizado, tais como creches e pré-escolas, bem como contribuir para a efetivação de políticas públicas de atendimento às díades mãe-bebê, por meio da atuação precoce junto ao núcleo familiar. Dessa forma, o presente estudo tem por objetivo conhecer e analisar as crenças maternas sobre o desenvolvimento sociocomunicativo do bebê nos três primeiros meses de vida, discutindo seu impacto nas interações mãe-bebê.

\section{Método}

\section{Delineamento do Estudo}

A presente pesquisa é de cunho qualitativo, que se refere à pesquisa que trabalha com investigações no universo de significações, anseios, crenças, valores e atitudes dos processos que não podem ser reduzidos à operacionalização de variáveis, voltando-se para subjetividade (Minayo, 1994). Apresenta um delineamento transversal, buscando obter informações sobre mudanças nos aspectos do desenvolvimento em um determinado momento histórico e fornecer informações sobre aspectos comparáveis em relação à idade (Cole \& Cole, 2004).

\section{Participantes}

Participaram deste estudo 20 mães de bebês na idade de 1 a 3 meses de vida, residentes na cidade de Campina Grande, PB. Foram utilizados os seguintes critérios de inclusão: ter mais de 20 anos de idade, ser casada ou viver em união estável, residir em domicílio próprio, e ter um bebê com até 3 meses de idade. Todas as mães referiram que seus bebês nasceram a termo e sem problemas de desenvolvimento.

\section{Instrumento}

Foi utilizado um questionário sociodemográfico e um roteiro de entrevista referente às crenças das mães sobre as práticas de cuidado dispensado ao seu bebê, suas concepções acerca do desenvolvimento deste e das habilidades sociocomunicativas dos mesmos. O roteiro de entrevista foi construído com base na literatura da área do desenvolvimento infantil e nos objetivos do presente estudo. As 12 questões que compõem esta entrevista abordam os seguintes aspectos: a descrição materna sobre o período gestacional, o cotidiano da mãe com o bebê, a descrição sobre como a mãe percebia o relacionamento dela com o bebê desde o nascimento e após um período, a descrição dos sentimentos maternos e de suas expectativas sobre o desenvolvimento infantil. Para o presente artigo foi feito um recorte que se concentrou nas questões relativas às práticas de cuidado parentais e à dimensão sociocomunicativa da linguagem, quais sejam: "você acha que o modo como você cuida do seu bebê nesses primeiros meses pode influenciar o desenvolvimento dele? Por quê?"; "Na sua opinião, o que seu bebê pode fazer para mostrar que deseja algo ou está precisando de você? (exemplifique)"; "Você acha que seu bebê compreende o que acontece no seu ambiente?". Essas duas últimas questões tiveram por base o instrumento The Pragmatics Profile of Everyday Communication Skills in Children (edição revisada de Dewart \& Summers, 1995). Este instrumento passou por um processo de adaptação semântica realizada por Braz Aquino e Salomão (2008) e consiste numa entrevista estruturada centrada nos aspectos sociopragmáticos da linguagem.

\section{Procedimento para Coleta e Análise dos Dados}

O presente trabalho foi aprovado pelo Comitê de Ética em Pesquisa do Centro de Ciências Biológicas e da Saúde, da Universidade Estadual da Paraíba sob CAEE 0313.0.133.000-09, respeitando os padrões éticos de conduta da resolução 196/96 do Ministério da Saúde. O contato com as mães foi feito por meio de indicação pessoal. Em seguida foi esclarecido a cada participante o objetivo da pesquisa, o sigilo dos conteúdos das respostas e o caráter voluntário da participação. Após o consentimento da mesma, 
foi solicitado que ela assinasse o Termo de Consentimento Livre e Esclarecido, confirmando seu aceite em participar da pesquisa. As entrevistas foram realizadas pela primeira autora, de forma individual, nas residências das mães. Todas as entrevistas foram gravadas e, posteriormente as respostas foram transcritas e organizadas para a análise. Antes, porém, foi realizado um estudo piloto com vistas a checar a adequabilidade semântica das questões que compunham a entrevista, não sendo relatadas pelas respondentes incompreensões ou dúvidas sobre as mesmas.

No que diz respeito à análise dos dados, foram seguidas as diretrizes do método de análise de conteúdo (Bardin, 1977/2002). As respostas foram analisadas qualitativamente, e organizadas de acordo com a frequência de respostas semanticamente semelhantes ou divergentes. Dos dados obtidos foram destacadas as seguintes categorias: crenças sobre a influência dos cuidados maternos para o desenvolvimento infantil; crenças maternas sobre as habilidades dos bebês para comunicarem suas necessidades às mães; e crenças maternas sobre as habilidades do bebê para compreender o meio no qual vive. Essas categorias, por seu turno, foram divididas em subcategorias mutuamente excludentes, ou seja, a resposta da mãe foi classificada apenas em uma subcategoria. Os resultados obtidos desta análise foram discutidos a partir dos dados da literatura na área.

\section{Resultados}

A análise do questionário sociodemográfico permitiu identificar características importantes da amostra. As mães participantes tinham idade média de 28,05 anos. Elas pertenciam a diferentes níveis socioeconômicos e tinham níveis de instrução que variaram entre o Ensino Fundamental $(n=1)$, Ensino Médio $(n=15)$ e Ensino Superior $(n=4)$. Catorze mães eram primíparas e seis tinham outro filho; 12 eram casadas e oito viviam em união estável com o pai da criança. Em relação ao sexo da criança, a amostra foi composta por 12 meninas e oito meninos. Destes, 11 estavam na idade entre $0-1$ mês, quatro na faixa etária entre 1 e 2 meses, e cinco entre 2 e 3 meses.

Especificamente no tocante às crenças maternas sobre o desenvolvimento, os relatos maternos permitiram a elaboração de três categorias, as quais são expostas na Tabela 1 e detalhadas na sequência.

Tabela 1

Categorias e Subcategorias sobre as Crenças Maternas acerca do Desenvolvimento Infantil

\begin{tabular}{|c|c|c|}
\hline Categorias & Subcategorias & Frequência \\
\hline \multirow{3}{*}{$\begin{array}{c}\text { Crenças sobre as consequências } \\
\text { dos cuidados maternos para } \\
\text { o desenvolvimento infantil }\end{array}$} & $\begin{array}{l}\text { O bom desenvolvimento da criança é influenciado } \\
\text { pelo carinho oferecido pela mãe }\end{array}$ & $50 \%$ \\
\hline & $\begin{array}{l}\text { Os cuidados maternos (alimentar, dar banho, trocar fralda) } \\
\text { influenciam o crescimento saudável da criança }\end{array}$ & $45 \%$ \\
\hline & $\begin{array}{l}\text { O modo como às mães educam o bebê desde o nascimento } \\
\text { influencia seu desenvolvimento }\end{array}$ & $5 \%$ \\
\hline \multirow{2}{*}{$\begin{array}{l}\text { Crenças maternas sobre } \\
\text { as habilidades dos bebês } \\
\text { para comunicarem suas } \\
\text { necessidades às mães }\end{array}$} & $\begin{array}{l}\text { O choro é um comportamento utilizado pelo bebê } \\
\text { para se comunicar e chamar a atenção das mães }\end{array}$ & $75 \%$ \\
\hline & $\begin{array}{l}\text { Tossir; gritar; olhar pra ela; fazer qualquer coisa pra chamar } \\
\text { atenção da mãe são comportamentos comunicativos }\end{array}$ & $25 \%$ \\
\hline \multirow{2}{*}{$\begin{array}{l}\text { Crenças maternas sobre } \\
\text { a habilidade do bebê para } \\
\text { compreender o meio } \\
\text { no qual vive }\end{array}$} & $\begin{array}{l}\text { O bebê entende o que acontece no ambiente } \\
\text { e o que elas conversam com ele }\end{array}$ & $70 \%$ \\
\hline & $\begin{array}{l}\text { O bebê ainda não é capaz de compreender o que acontece } \\
\text { no ambiente nem o que ela conversa com ele }\end{array}$ & $30 \%$ \\
\hline
\end{tabular}


A Tabela 1 exibe o resultado das análises das entrevistas por meio das quais emergiram as crenças maternas sobre o desenvolvimento infantil e a frequência que cada uma dessas crenças apareceu nos relatos maternos. No que tange às Crenças sobre as consequências dos cuidados maternos para o desenvolvimento infantil, observou-se que $100 \%$ das mães pensam que seus cuidados influenciam o desenvolvimento infantil. Parte dessas mães (50\%) acredita que o bom desenvolvimento da criança está diretamente relacionado ao carinho que elas oferecem ao bebê, como na fala a seguir: "Acho que sim, porque dependendo do carinho que você der, toda atenção, todo cuidado influencia o crescimento" (E16)

Outras mães (45\%) afirmam que os cuidados maternos, tais como alimentar, dar banho, trocar fraldas influenciam o crescimento saudável do seu bebê. Ou seja, estas mães percebem que o modo como cuidam do bebê é o que subsidia o desenvolvimento do mesmo, como ilustrado nessa fala: "Sim, se você cuida direitinho da alimentação, cuida dele, dando banho, dando a comidinha na hora certa ele cresce saudável" (E18).

Ainda foi observado que $5 \%$ das mães do estudo relatam que o modo como elas educam o bebê desde o início da vida do mesmo é o que influencia seu desenvolvimento.

Em relação às crenças maternas sobre as habilidades dos bebês para comunicarem suas necessidades às mães, a maioria delas (75\%) afirmou que o bebê apenas chora quando precisa se comunicar e chamar a atenção das mães. Uma vez que ele ainda não pode falar, o choro é o sinalizador de fome, dor, sono, desconforto e parece ter diferentes funções, como no exemplo: "Acho que ela chora demais, é por enquanto ele só sabe fazer isso, chorar" (E15).

Outros comportamentos sociocomunicativos descritos por parte das mães (25\%) foram tossir; gritar; olhar pra ela; fazer qualquer coisa pra chamar atenção da mãe, como ilustrado na fala seguinte:

Ela faz tanta coisa, ela grita. Ela chorava muito quando era menor [com um mês], hoje ela grita [com três meses], eu acho que é chamando. Quando a gente sai ela grita, acho que faz isso pra chamar. Finge que tá tossindo só pra gente ir lá. (E2)

No tocante às crenças maternas sobre a habilidade do bebê para compreender o meio no qual vive, perguntou-se às mães se estas consideravam que seu bebê seria capaz de compreender o que acontece no ambiente. Dentre as respostas das mães, 70\% relatou que o bebê entende o que acontece no ambiente e o que elas conversam com ele, como pode ser visualizado no exemplo: Agora sim [3 meses], antes não [com 1 e 2 meses]. De uns dias pra cá ele entende, porque até dois meses ele olhava, mas não tinha uma certa noção, agora sim, ele interage, ele olha, ele vê quem chega, fica olhando o ambiente, se tem desenho ele fica bem agitadozinho. Interessante, eu coloquei umas letras coloridas aqui na parede pro aniversário da minha filha e ele olhava e fazia a maior festa quando via, olhava tanto, mas ontem quando ele olhou e não viu ele chorou tanto que me arrependi de ter tirado, ele olhava como se tivesse procurando. De uns dias pra cá ele percebe, sabe. (E5)

Entretanto, $30 \%$ das mães entrevistadas afirmaram que o seu bebê ainda não é capaz de compreender o que acontece no ambiente nem o que ela conversa com ele. $\mathrm{O}$ relato abaixo mostra as crenças das mães sobre este aspecto: "Creio que ela não entende, ela fica escutando, é muito esperta, mas não entende porque não tem idade [1 mês] pra isso" (E4).

Estes resultados são discutidos na seção a seguir, quando serão resgatadas teorias e pesquisas na área.

\section{Discussão}

Inicialmente considerou-se pertinente explorar, do conjunto de dados obtidos neste estudo, os aspectos: idade do bebê, idade materna e escolaridade materna, dado que a literatura, como já mencionado, refere como influenciando as crenças parentais.

Em relação a esses fatores, foi possível observar que quanto mais idade possuía o bebê, mais se ampliavam os conhecimentos maternos 
sobre os comportamentos do mesmo. De forma geral, as mães de bebês com mais de dois meses de idade apresentaram mais elementos do dia-a-dia do bebê para ilustrar suas respostas. Por outro lado, as mães de bebês com menos de um mês emitiram descrições mais breves, tais como dar apenas uma característica do desenvolvimento ou não mencionar exemplos para ilustrar sua fala. Estes dados corroboram o estudo realizado anteriormente por Seidl de Moura, Ribas, Piccinini, et al. (2004), no qual os autores mencionam que, com o avanço na idade do bebê, a mãe parece ter mais conhecimentos sobre o mesmo. Para estes autores, tal fato sugere que não é só a mãe que influencia o bebê, mas que as características ou pistas dadas pelo mesmo também podem afetar as crenças maternas. A partir deste movimento de se aproximar e conhecer o bebê, esperar respostas dele e oferecer antecipadamente um modelo de interação, estabelece-se um padrão de relação mãe-bebê (Piccinini, Levandowski, Gomes, Lindenmeyer, \& Lopes, 2009).

Com relação à idade materna verificou-se que as mães com mais idade não demonstraram ter maior conhecimento sobre desenvolvimento infantil do que as mães mais jovens, no caso de serem mães primíparas. Nos casos das mães secundíparas observou-se que estas, independente da idade, tinham mais informações sobre as características do desenvolvimento do bebê em função de sua experiência com o filho anterior. Assim como nos achados de Silva (2003), nesta pesquisa verificou-se que as diferenças de idades das mães não foram necessariamente um elemento que influenciou seu conhecimento sobre desenvolvimento infantil.

No que diz respeito à escolaridade, notou-se que as mães com maior nível de escolaridade apresentaram respostas mais organizadas e com mais informações a respeito do comportamento do seu bebê, exibindo uma maior facilidade de refletir sobre a pergunta e falar do seu bebê quando a questão lhe era dirigida. As mães com menor nível de escolaridade pareciam estar inseguras para responder a entrevista, muitas inclusive, começando a resposta dizendo "eu não sei", para somente em seguida falar o que realmente pensavam ou sentiam com relação ao bebê. É importante referir que para pesquisadores como Reznick e Schwartz (2001), a própria entrevista se constitui num meio de intervenção pois, segundo afirmam, as perguntas feitas sobre os aspectos do desenvolvimento do bebê durante as entrevistas podem ter um efeito interventivo na medida em que levam as mães a pensarem em aspectos da vida do bebê e da sua relação com ele, antes não considerados ou conhecidos por ela.

Os dados deste estudo confirmam outras pesquisas na área (Kobarg \& Vieira, 2008; Seidl de Moura, Ribas, Piccinini, et al., 2004; Silva, 2003) que reconhecem a importância da escolaridade materna como variável diretamente relacionada aos conhecimentos maternos sobre desenvolvimento infantil. Na presente pesquisa, as mães que possuíam maior grau de instrução foram as mães que, na ocasião da entrevista, puderam dar mais informações sobre o desenvolvimento do seu bebê. Kobarg e Vieira (2008) afirmam que o nível de escolaridade é inclusive até mais importante que outros aspectos contidos na interação mãe-criança, pois envolve um sistema diferenciado de valores, crenças e, por conseguinte, de práticas de socialização. É importante ressaltar que o nível de escolaridade maior não significa, necessariamente, mais conhecimentos sobre o desenvolvimento infantil. Deve-se considerar que o maior nível de escolaridade pode fazer com que estas mães tornem-se, em alguns casos, mais a vontade para expressar suas concepções; ou que tenham maior facilidade de elaborar sua resposta.

Os resultados apresentados sobre a categoria referente às crenças sobre as consequências dos cuidados maternos para o desenvolvimento infantil ganham apoio na ideia já citada de Bowlby (1984/2002) o qual afirma que os cuidados maternos estão fortemente ligados ao comportamento de apego, sendo os cuidados da mãe com o bebê um meio para que ela fique próxima do mesmo, estando assim, sempre atenta às necessidades do filho e pronta para supri-las. Para Brum e Schermann (2004) quando o bebê está seguro de que suas necessidades serão satisfeitas, ele começa a desenvolver um sentimento de confiança que o conduz a construção da sua 
independência, e então ele começa a usar sua curiosidade, pela base segura formada com seu cuidador, para desbravar e experimentar o mundo. De fato, todos os aspectos citados pelas mães influenciam de algum modo o desenvolvimento da criança. Desta maneira, observa-se que além de fatores como afeto, educação e cuidado, o modo de vida da mãe ou da família como um todo, citados pela maioria das mães do estudo, irá influenciar o desenvolvimento infantil, através das crenças parentais, costumes do cuidador e do contexto geral no qual a criança irá viver (Harkness \& Super, 1996, 2006).

No que se refere aos resultados apresentados pelas mães na categoria crenças maternas sobre as habilidades dos bebês para comunicarem suas necessidades às mães, conforme afirma Bowlby (1984/2002) o choro pode ter diferentes significados (fome, dor, sono) e ocorrem para demonstrar as diferentes necessidades do bebê; para ele é possível distingui-los através da intensidade de cada um, pois de acordo com este autor, um choro de fome é mais intenso e aumenta aos poucos, um choro de dor é mais alto e não para mesmo quando o bebê é alimentado. Cole e Cole (2004) lembram que os bebês choram porque ainda não são capazes de expressar verbalmente como estão se sentindo, mas têm uma maneira importante de demonstrar que algo está errado por meio do choro.

Brazelton (1994) menciona a importância das mães saberem identificar o que cada choro quer dizer, pois assim ela poderá atender a demanda do bebê. Este autor lembra que não há uma fórmula mágica para se descobrir o que cada choro sinaliza, a única maneira que a mãe tem de descobrir é por tentativa e erro e por atribuição de significado.

Além do choro, os outros comportamentos apresentados pelas mães, como tossir, gritar e o uso de gestos fornecem pistas para que as mães interpretem essas ações de acordo com o contexto e atribuam significados comunicativos a esses comportamentos (Pessôa et al., 2008; Slaughter et al., 2009). Essas atribuições contribuem de forma positiva no processo interacional. Nesse sentido, Bowlby (1984/2002) afirma que o chorar, sorrir e balbuciar e, posteriormente, chamar e fazer certos gestos, são considerados como sinais sociais, tendo como resultado provável o aumento da proximidade da mãe com a criança.

No tocante às crenças maternas sobre a habilidade do bebê para compreender o meio no qual vive, percebe-se nos relatos das participantes que a maioria das mães acredita que o bebê desde cedo tem a possibilidade de entender o que ocorre no ambiente, e essa crença pode ser vista como um fator positivo na relação mãe-bebê, pois, conforme Brazelton (1994), compreender a maneira como um recém-nascido lida com o ambiente em que vive dá aos pais e aos cuidadores dele um sentimento de respeito pela sua competência.

Os dados encontrados também remetem à habilidade de atenção seletiva do bebê, que segundo Bowlby (1984/2002) faz com que o bebê preste atenção em algumas partes do ambiente apenas. Legerstee (2013) esclarece que as competências precoces dos bebês estão relacionadas à atenção e à discriminação do ambiente de modo que os mesmos respondem seletivamente a estímulos sociais. Parece existir um interesse do bebê pela voz e face humanas, particularmente se tratando da sua mãe (Bornstein, 2013; Cole \& Cole, 2004; Klaus \& Klaus, 2001; Legerstee, 2013).

Sobre esse aspecto, Bornstein (2013), afirma que as representações que a mãe tem das capacidades sensório-perceptivas do recém-nascido baseiam-se, fundamentalmente, em índices comportamentais objetivos observados no comportamento do filho, dando ao bebê um papel de agente ativo no estabelecimento das relações recíprocas.

Seidl de Moura, Ribas, Seabra, et al., (2004) lembram que o bebê é um sujeito essencialmente ativo, que age e não apenas reage, sendo capaz cada vez mais de compartilhar um número maior de contextos de interação. Segundo os autores, ele interage não apenas com a mãe, mas com os novos contextos que o envolvem, ampliando seus processos de socialização. Isso é demonstrado por volta dos três meses quando os bebês evidenciam uma sensibilidade aos estímulos sociais, tais como o contato visual e características vocais para compreender a relevância dos sinais 
sociais necessários para a aprendizagem e comunicação (Cleveland et al., 2007).

Para Silva (2003), as mães precisam conversar com seus filhos, mesmo que estes sejam recém-nascidos, pois a criança aprende a vocalizar, imitando os sons ouvidos no meio. A necessidade de dialogar faz com que mãe e criança aprendam a responder uma à outra por meio da repetição de comportamentos que poderão ocorrer nas situações de interação. Diante disso, considera-se fundamental pontuar que o desenvolvimento das habilidades sociocomunicativas e cognitivas nos primeiros meses de vida do bebê pode ser favorecido e potencializado pelas crenças maternas e pelas configurações específicas das trocas que ocorrem entre os bebês e seus cuidadores.

\section{Considerações Finais}

A presente pesquisa procurou investigar as crenças maternas sobre o desenvolvimento sociocomunicativo do bebê nos primeiros meses de vida. Os resultados mostram que as mães secundíparas e as mães de maior grau de instrução demonstraram ter mais conhecimentos sobre as características do desenvolvimento infantil, o que evidencia que as variáveis, escolaridade e número de filhos são importantes no estudo das crenças maternas sobre o desenvolvimento infantil e, possivelmente, nos tipos de interações que se estabelecem entre as díades.

As habilidades do bebê, que surgem ao longo de desenvolvimento por meio das interações sociais, possibilitam mudanças qualitativas no modo como as mães percebem seus filhos, o que demonstra o caráter bidirecional dessas interações. No presente estudo, a maioria das mães compartilha a crença de que já nos três primeiros meses os bebês são capazes de compreender o que acontece no ambiente e entender o que elas conversam com eles. Elas concebem que o bebê usa o choro, os gritos e o olhar para se comunicar. Para estas mães, o modo como elas cuidam do seu filho nos primeiros meses, a educação que oferecem, o amor que dedicam ao filho influenciam o desenvolvimento do mesmo.
Observou-se que as mães entrevistadas possuem conhecimentos que condizem com o processo real do desenvolvimento sociocomunicativo do bebê, tais como conceber que o modo como cuidam do bebê influencia seu desenvolvimento. Assim, pode-se sugerir que as crenças maternas sobre o desenvolvimento do bebê guiam seus modos de cuidar da criança e influenciam o desenvolvimento da mesma, tal como relatado pela literatura na área.

Os resultados encontrados no presente estudo trazem dados empíricos sobre as crenças maternas acerca do bebê nos três primeiros meses de vida e contribuem com a literatura sobre os aspectos parentais que influenciam o desenvolvimento infantil, auxiliando o (a) psicólogo (a) no planejamento de intervenções nas áreas de saúde e educação (berçários e creches), que busquem orientar pais e educadores infantis sobre as potencialidades do bebê desde os primeiros meses de vida e a importância desse conhecimento para melhoria das interações adulto-bebê/ criança. Esse conhecimento e o diálogo com o profissional de psicologia pode contribuir para a identificação e tratamento precoces de sinais indicadores de dificuldades e/ou transtornos do desenvolvimento.

Nesse sentido, destaca-se a relevância de pesquisas que fundamentem a atuação de psicólogos em serviços públicos e privados que visam promover assistência contínua às gestantes e mães de bebês no primeiro ano de vida, pelo potencial que tem as interações adulto-criança para o desenvolvimento posterior. Além disso, ressalta-se que as entrevistas realizadas com as mães podem ter representado também uma forma de intervenção, como defendem Reznick e Schwartz (2001). As perguntas feitas às mães participantes do estudo podem ter esse efeito interventivo, tendo em vista que possibilitam que as mães reflitam sobre aspectos da vida do bebê e da sua relação com ele, algo que antes poderia não ocorrer com elas.

Entretanto, como limitação da presente pesquisa aponta-se a necessidade de realizar estudos com populações de diferentes níveis de instrução e extratos sociais, no contexto rural e urbano e 
ainda que abarquem um maior número de sujeitos, na perspectiva de identificar aspectos que não foram apreendidos por meio do roteiro de entrevista proposto, como também levantar possíveis sinais, sintomas e prejuízos na comunicação e linguagem, por meio do relato materno.

Ademais, pontua-se que o discurso de algumas mães pode expressar pouca clareza acerca da habilidade de comunicação do bebê nos primeiros meses de vida, e suas respostas podem remeter a formas de pensar a criança nesse período, às práticas de criação socialmente transmitidas em seu entorno e aos sistemas de informações aos quais tem acesso. Pontua-se ainda que parte dessas mães pode ter emitido respostas que pensam ser socialmente aceitas e esperadas pelo pesquisador. Nessa perspectiva, ressalta-se a necessidade de divulgar, para as mães e para a população como um todo, a importância dos cuidados parentais e da qualidade das experiências que os bebês compartilham com o os adultos nos primeiros meses de vida.

Diante disso, sugerem-se futuros estudos na área abrangendo uma amostra que inclua a figura paterna, bem como grupos que representem as configurações familiares das últimas décadas. Incluir o pai em estudos como este pode trazer novas informações à literatura e contribuir para um entendimento maior sobre o conhecimento paterno acerca do comportamento do bebê, além de possibilitar a compreensão mais adequada dos elementos potencializadores do desenvolvimento nas interações iniciais infantis.

\section{Referências}

Alvarenga, P., \& Piccinini, C. A. (2007). O impacto do temperamento infantil, da responsividade e das práticas educativas maternas nos problemas de externalização e na competência social da criança. Psicologia: Reflexão e Crítica, 20(2), 314-323.

Amorim, K. S., Costa, C. A., Rodrigues, L. A., Moura, G. G., \& Ferreira, L. D. P. M. (2012). O bebê e a construção de significações, em relações afetivas e contextos culturais diversos. Temas em Psicologia, 20(2), 309-326.
Bandeira, T. T. A., Seild-de-Moura, M. L., \& Vieira, M. L. (2009). Metas de socialização de pais e mães para seus filhos. Revista Brasileira de Crescimento e Desenvolvimento Humano, 19(3), 445-456.

Barbosa, S. C. O. (2010). Relações entre o temperamento infantil e as práticas educativas maternas: Estudo longitudinal dos oito aos 18 meses de vida (Dissertação de mestrado, Instituto de Psicologia, Universidade Federal da Bahia, Salvador, BA, Brasil).

Bardin, L. (2002). Análise de conteúdo (L. Antero Neto \& A. Pinheiro, Trads.). São Paulo, SP: Martins Fontes. (Original publicado em 1977)

Bornstein, M. H. (2013). Mother - Infant attunement: A multilevel approach via body, brain, and behavior. In M. Legerstee, D. Haley, \& M. H. Bornstein (Eds.), The infant mind: Origins of the social brain (pp. 266-289). New York: The Guilford Press.

Bornstein, M. H., \& Tamis-Lemonda, C. S. (1997). Maternal responsiveness and infant mental abilities: Specific predictive relations. Infant Behavior and Development, 20(3), 283-296.

Bowlby, J. (2002). Apego e perda (3. ed., A. Cabral, Trad.). São Paulo, SP: Martins Fontes. (Original publicado em 1984)

Braz Aquino, F. de S., \& Salomão, N. M. R. (2008). Intencionalidade comunicativa e atenção conjunta: Uma análise em contextos interativos mãe-bebê (Tese de doutorado, Programa Integrado de Doutorado em Psicologia Social, Universidade Federal da Paraíba, João Pessoa, PB, Brasil).

Brazelton, T. B. (1994). Momentos decisivos do desenvolvimento infantil (J. L. Camargo, Trad.) São Paulo, SP: Martins Fontes.

Brum, E. H. M., \& Schermann, L. (2004). Vínculos iniciais e desenvolvimento infantil: Abordagem teórica em situação de nascimento de risco. Ciência \& Saúde Coletiva, 9(2), 457-467.

Cleveland, A., Schug, M., \& Striano, T. (2007). Joint attention and object learning in 5- and 7-monthold infants. Infant and Child Development, 16, 295-306.

Cole, M., \& Cole, S. R. (2004). O desenvolvimento da criança e o do adolescente (M. F. Lopes, Trad.). Porto Alegre, RS: Artmed. 
Dewart, H., \& Summers, S. (1995). The pragmatics profile of everyday communication skills in children (Rev. ed.). Windsor, UK: Nfer-Nelson.

Gratier, M., \& Trevarthen, C. (2007). Voice, vitality and meaning: On the shaping of the infant's utterances in willing engagement with culture. Comment os Bertaus's "on the notion of voice". International Journal for Dialogical, 2(1), 169181.

Harkness, S., \& Super, C. M. (1996). Parents' cultural belief systems: Their origins, expressions, and consequences. New York: The Guilford Press.

Harkness, S., \& Super, C. M. (2006). Themes and variations: Parental ethnotheories in Western Cultures. In K. H. Rubin \& O. B. Chung (Eds.), Parental beliefs, behavior, and parent-child relations: A cross-cultural perspective (pp. 6180). New York: Routledge.

Klaus, M. H., \& Klaus, P. H. (2001). Seu surpreendente recém-nascido (M. A. V. Veronese, Trad.). Porto Alegre, RS: Artmed.

Kobarg, A. P. R., \& Vieira, M. L. (2008). Crenças e práticas de mães sobre o desenvolvimento infantil nos contextos rural e urbano._Psicologia: Reflexão e Crítica, 21(3), 401-408.

Kobarg, A. P. R., Vieira, M. L., \& Sachetti, V. A. (2006). Valores e crenças parentais: Reflexões teóricas. Revista Brasileira de Crescimento e Desenvolvimento Humano, 16(2), 96-102.

Legerstee, M. (2013). The developing social brain: Social connections and social bonds, social loss, and jealousy in infancy. In M. Legerstee, D. Haley, \& M. H. Bornstein (Eds.), The infant mind: Origins of the social brain (pp. 223-247). New York: The Guilford Press.

Magalhães, C. M. C. (2007). Crenças parentais quanto à mesada (Dissertação de mestrado, Instituto de Filosofia e Ciências Humanas, Universidade Federal do Pará, Belém, PA, Brasil).

Mendes, D. M. L. F., \& Seidl Moura, M. L. (2009). Expressões faciais de emoção em bebês: Importância e evidências. Estudos e Pesquisas em Psicologia, 9, 307-327.

Minayo, M. C. S. (1994). Pesquisa social: Teoria, método e criatividade. Petrópolis, RJ: Vozes.

Nogueira, S. E., \& Seidl de Moura, M. L. (2007). Intersubjetividade: Perspectivas teóricas e implicações para o desenvolvimento infantil inicial.
Revista Brasileira de Crescimento e Desenvolvimento Humano, 17(2), 128-138.

Pessôa, L. F., Seidl de Moura, M. L., \& Oliva, A. D. (2008). A análise da fala materna dirigida a bebês em duas etapas do desenvolvimento. Psicologia em Pesquisa, 2(2), 74-86.

Piccinini, C. A., Levandowski, D. C., Gomes, A. G., Lindenmeyer, D., \& Lopes, R. S. (2009). Expectativas e sentimentos de pais em relação ao bebê durante a gestação. Estudos de Psicologia (Campinas), 26(3), 373-382.

Pino, A. (2005). As marcas do humano: As origens da constituição cultural da criança na perspectiva de Lev S. Vigotski. São Paulo, SP: Cortez.

Piovanotti, M. R. A. (2007). Crenças maternas sobre práticas de cuidado parental e metas de socialização infantil (Dissertação de mestrado, Universidade Federal de Santa Catarina, Florianópolis, $\mathrm{SC}$, Brasil).

Pires, A. (1990). Determinantes do comportamento parental. Análise Psicológica, 4(8), 445-452

Reznick, J. S., \& Schwartz, B. B. (2001). When is an assessment an intervencion? Parent perception of infant intentionality and language. Journal of the American Academy of Child and Adolescent Psychiatry, 40(1), 11-17.

Ribas, R. C., Jr., Seidl-de-Moura, M. L., \& Bornstein, M. H. (2007). Cognições maternas acerca da maternidade e do desenvolvimento humano: Uma contribuição ao estudo da psicologia parental. Revista Brasileira de Crescimento e Desenvolvimento Humano, 17(1), 104-111.

Rossetti-Ferreira, M. C., \& Costa, N. R. A. (2012). Construcción de vínculos afectivos en contextos adversos de desarrollo: importancia y polémicas. Scripta Nova: Revista Electrónica de Geografia y Ciencias Sociales, 395(2).

Seidl de Moura, M. L. (1999). Interações iniciais e seu papel no desenvolvimento: Uma contribuição ao estado da gênese da atividade mediada (Tese de livre docência, Universidade Estadual do Rio de Janeiro, RJ, Brasil).

Seidl de Moura, M. L., Ribas, A. F. P., Seabra, K. C., Pessôa, L. F., Ribas, R. C., Jr., \& Nogueira, S. E. (2004). Interações iniciais mãe-bebê. Psicologia: Reflexão e Crítica, 17(3), 295-302.

Seidl de Moura, M. L., Ribas, R. C., Jr., Piccinini, C. A., Bastos, A. C. S., Magalhães, C. M.C., Vieira, M. L., ...Silva, A. K. (2004). Conhecimento so- 
bre desenvolvimento infantil de mães primíparas de diferentes centros urbanos do Brasil. Estudos de Psicologia (Natal), 9(3), 421-429.

Silva, A. K. (2003). Concepções de mães primíparas sobre o desenvolvimento infantil ao longo do primeiro ano de vida da criança (Dissertação de mestrado, Universidade Federal de Santa Catarina, Florianópolis, SC, Brasil).

Slaughter, V., Peterson, C. C., \& Carpenter, M. (2009). Maternal mental state talk and infants' early gestural communication. Journal of Child Language, 36, 1053-1074.

Striano, T., \& Reid, V. (2006). Social cognition in the first year. Trends in Cognitive Sciences, 10(10), $471-476$

Trevarthen, C. (1979). Communication and cooperation in early infancy: A description of primary intersubjectivity. In M. Bullowa (Ed.), Before speech: The beginning of interpersonal communication (pp. 321-348). Cambridge, UK: Cambridge University Press.
Trevarthen, C., \& Aitken, K. J. (2001). Infant intersubjectivity: Research, theory, and clinical applications. Journal of Child Psychology and Psychiatry, 42(1), 3-48.

Zamberlan, M. A. T. (2002). Interação mãe-criança: Enfoques teóricos e implicações decorrentes de estudos empíricos. Estudos de Psicologia (Natal), 7(2), 399-406.
Recebido: 02/09/2013

$1^{a}$ revisão: $11 / 11 / 2013$

$2^{a}$ revisão: $12 / 12 / 2013$

$3^{a}$ revisão: $24 / 02 / 2014$ Aceite final: 05/03/2014 